\title{
Biomassa, trocas gasosas e aspectos nutricionais de plantas jovens de pau de balsa (Ochroma pyramidale (Cav. Ex Lamb.) Urb.) submetidas à fertilização fosfatada em ambientes contrastantes de irradiância
}

\author{
Biomass, gas exchange and nutritional aspects of young plants of \\ Balsa Wood (Ochroma pyramidale (Cav. Ex Lamb.) Urb.) subjected \\ to phosphorus fertilization in contrasting irradiance environments
}

\author{
Hellen Fernanda Viana Cunha ${ }^{1}$, José Francisco de Carvalho Gonçalves ${ }^{2}$, \\ Ulysses Moreira dos Santos Junior ${ }^{3}$, Marciel José Ferreira ${ }^{4}$ e Paulo Henrique Pereira Peixoto ${ }^{5}$
}

\begin{abstract}
Resumo
A intensidade de irradiância e o fornecimento de nutrientes afetam a assimilação de carbono e alteram o ganho e a partição de biomassa das plantas. $\mathrm{O}$ objetivo desta pesquisa foi investigar o crescimento e a fotossíntese em plantas jovens de Ochroma pyramidale submetidas a ambientes contrastantes de luz e de fertilização fosfatada. Plantas jovens de Ochroma pyramidale foram expostas a dois níveis de irradiância (baixa: 10 a 15 e alta: 1200 a $1400 \mu$ mol fótons $\mathrm{m}^{-2} \mathrm{~s}^{-1}$ ) e a dois níveis de fertilização fosfatada (0 e $1 \mathrm{mM}$ de $\mathrm{KH}_{2} \mathrm{PO}_{4}$ ), durante 160 dias. $\mathrm{O}$ delineamento experimental utilizado foi o inteiramente casualizado em esquema fatorial (2x2), com 10 repetições. O maior crescimento em altura e em diâmetro foi observado nas plantas de 0 . pyramidale fertilizadas com fósforo e submetidas à alta irradiância. Quanto à alocação de massa seca, plantas sob alta irradiância investiram mais em fração de massa radicular e as plantas sob baixa irradiância em fração de massa foliar. Para os teores foliares de $P$, as plantas fertilizadas com $P$ exibiram valores 137 e $54 \%$ superiores às plantas não fertilizadas com $P$, sob alta e baixa irradiância, respectivamente. A ausência de $\mathrm{P}$ na fertilização promoveu intensa redução na eficiência fotoquímica do fotossistema II bem como nas taxas fotossintéticas. A maior produção de biomassa e assimilação de carbono nas plantas com fósforo sob maior nível de irradiância sugerem que plantas de O. pyramidale possuem mecanismos funcionais para exibir melhor desempenho funcional e de crescimento em áreas abertas (alta irradiância), típicas de plantios florestais ou de ambientes em processo de recuperação.
\end{abstract}

Palavras-chave: crescimento, fotossíntese, luz, fósforo.

\begin{abstract}
The irradiance and nutrient supply affect the assimilation of carbon and influence the gain and biomass partition. The aim of this research was to investigate the growth and photosynthesis in young plants of Ochroma pyramidale subjected to contrasting light environments and phosphorus fertilization. Young plants of O. pyramidale were exposed to two irradiance levels (Low: 10 to 15 and High: 1200 to $1400 \mu \mathrm{mol} \mathrm{m}^{-2}$ $\mathrm{s}^{-1}$ ) and two levels of $\mathrm{P}$ fertilization ( 0 and $1 \mathrm{mM}$ as $\mathrm{KH}_{2} \mathrm{PO}_{4}$ ) for 160 days. The experimental design was a completely randomized in factorial arrangement $(2 \times 2)$, with 10 replications. The greatest growth in height and diameter was observed in plants fertilized with phosphorus and under high irradiance. Concerning the allocation of dry mass, plants under high irradiance invested more in root mass ratio and plants under low irradiance in leaf mass ratio. For foliar $\mathrm{P}$ content, the plants fertilized with $\mathrm{P}$ exhibited values 137 and $54 \%$ higher than the plants not fertilized with $\mathrm{P}$, under high and low irradiance, respectively. The absence of $P$ fertilization promoted intense reduction in the efficiency of electron transport, as demonstrated by the values of photochemical efficiency of photosystem II, and photosynthetic rates. The greatest biomass production and higher photosynthetic rates in plants fertilized with phosphorus and under higher irradiance suggest that $O$. pyramidale plants have appropriate functional mechanisms to show a better growth and physiological performance in open fields (high irradiance), common in forest plantations or environments in recovery process.
\end{abstract}

Keywords: growth, photosynthesis, light, phosphorus.

${ }^{1}$ Mestre em Ciências de Florestas Tropicais. INPA - Instituto Nacional de Pesquisas da Amazônia. Av. André Araújo, 2936 69060-001 - Manaus, AM, Brasil. E-mail: hfcunha.florestal@gmail.com

${ }^{2}$ Doutor em Fisiologia Vegetal. INPA - Instituto Nacional de Pesquisas da Amazônia. Caixa Postal 478 - 69011-970 - Manaus, AM, Brasil. E-mail: jfc@inpa.gov.br * autor para correspondência

${ }^{3}$ Doutor em Ciências de Florestas Tropicais. INPA- Instituto Nacional de Pesquisas da Amazônia. Caixa Postal 478 - 69011 970 - Manaus, AM, Brasil. E-mail: santosjunior.ulysses@gmail.com

${ }^{4}$ Doutor em Ciências de Florestas Tropicais. UFAM - Universidade Federal do Amazonas. Avenida Gal. Rodrigo Otávio Jordão Ramos, 3000 - 69077-000 - Manaus, AM, Brasil. E-mail: marciel@ufam.edu.br

${ }^{5}$ Doutor em Fisiologia Vegetal. UFJF - Universidade Federal de Juiz de Fora / Campus Universitário - 36.036-900 - Juiz de Fora, MG, Brasil. E-mail: paulo.peixoto@ufjf.edu.br

Sci. For., Piracicaba, v. 44, n. 109, p. 215-230, mar. 2016 DOI: dx.doi.org/10.18671/scifor.v44n109.21 
Cunha et al. - Biomassa, trocas gasosas e aspectos nutricionais de plantas jovens de pau de balsa (Ochroma pyramidale (Cav. Ex Lamb.) Urb.) submetidas à fertilização fosfatada em ambientes contrastantes de irradiância

\section{INTRODUÇÃO}

Na Amazônia, as áreas já desflorestadas podem ser inseridas no processo de produção a partir de investimentos técnicos e científicos em plantios florestais, ajustando assim o atual enfoque da silvicultura tropical, que tem desempenhado, até então, papel mais relevante na recuperação e/ou restauração de áreas alteradas/degradadas, conforme tem sido descrito na literatura (SANTOS JR. et al., 2006; FERREIRA et al., 2012; JAQUETTI et al., 2014, ZAHAWI et al., 2015). Para tanto, maior atenção precisa ser dada aos estudos de ecofisiologia florestal que possam auxiliar na seleção de espécies arbóreas a serem utilizadas com sucesso nos plantios, relacionando os fatores físicos do meio com as respostas fisiológicas das diferentes espécies arbóreas que podem ser introduzidas na cadeia de produção florestal (CRAVEN et al., 2011; GONÇALVES et al., 2012; AZEVEDO, 2014).

O sucesso na utilização de espécies nativas em plantios florestais exige informações sobre a silvicultura das mesmas nos diversos campos do conhecimento, e os requerimentos nutricionais tornam-se aspectos relevantes quando se trata de solos amazônicos, haja vista as reconhecidas limitações de fertilidade desses solos, especialmente, do nutriente fósforo (TOWNSEND et al., 2011; CRUZ et al., 2012; FONTES et al., 2013). Além disso, em condições de campo, irradiâncias elevadas podem comprometer processos fundamentais das plantas, havendo necessidade de se determinar o grau de tolerância/exigência por luz para as diferentes espécies (AZEVEDO, 2014). A quantidade reduzida de informações sobre as respostas ecofisiológicas de espécies nativas a fatores primários como nutrientes e luz, quase sempre, traz conseqüências negativas para tomada de decisão e limita a realização de plantios florestais em áreas tropicais (GYIMAH; NAKAO, 2007).

No que concerne aos nutrientes e aos solos amazônicos, que são caracterizados pela elevada acidez e baixa fertilidade, verifica-se que o crescimento vegetal pode ser comprometido pela limitação na disponibilidade de nutrientes no solo (MENDONÇA SANTOS et al., 2006). Dentre os nutrientes necessários ao crescimento e desenvolvimento vegetal, o fósforo (P) é aquele que requer maior atenção na Amazônia, devido ao baixo teor nos solos das regiões tropicais (QUESADA et al., 2012), limitando a produtividade das plantas em diferentes condições de sítio (LAMBERS et al., 2008; PLASSARD; DELL, 2010).

A baixa disponibilidade de $\mathrm{P}$ afeta diretamente a fotossíntese pela redução de trioses fosfato usadas durante a regeneração da ribulose 1,5 bisfosfato (RuBP) e diminuição no consumo e produção de ATP e NADPH, além de induzir a geração de radicais livres que podem causar danos fotoxidativos (REICH et al., 2009; DOMINGUES et al., 2010, HERNÁNDEZ; MUNNÉ-BOSCH, 2015). Por outro lado, plantas com adequado suprimento de $\mathrm{P}$ foliar, exibem incremento na assimilação de $\mathrm{CO}_{2}$, na eficiência de carboxilação e no processo fotoquímico, o que influencia o ganho de biomassa pelas plantas (DOMINGUES et al., 2010; WARREN, 2011).

Por sua vez, o ambiente lumínico interfere nas trocas gasosas e no crescimento podendo induzir modificações na partição de biomassa (GYMAH; NAKAO, 2007; LIMA et al., 2008). A luz não somente fornece a energia luminosa para assimilação do carbono, como também é importante na absorção e no transporte de nutrientes, além de regular o metabolismo do carbono, particularmente, na ativação de enzimas chaves envolvidas na etapa bioquímica do processo (SCHURMANN, 2003; LEE, 2013). Portanto, estudos que estabeleçam relações causais entre os fatores abióticos como luz e nutrientes precisam ser melhor explorados, especialmente, quando se trata de espécies arbóreas tropicais.

Na Amazônia, espécies arbóreas de alto desempenho, em termos de crescimento, têm sido utilizadas em plantios de recuperação de áreas alteradas, com destaque para Ochroma pyramidale, uma espécie pioneira e de rápido crescimento (COSTA et al., 2012), além de apresentar tolerância a luminosidade direta (MARENCO et al., 2001). A espécie pertence à família Malvaceae e tem sido utilizada para ampla variedade de fins comerciais como construção naval (barcos, jangadas), aérea e civil (isolantes térmicos e acústicos) reunindo importantes características econômicas para o setor florestal (MIDGLEY et al., 2010).

Diante do exposto, acredita-se que a partir dos conhecimentos sobre as demandas fisiológicas relacionadas ao rápido crescimento de espécies florestais é possível prever e até mesmo contornar eventuais dificuldades nos plantios, em particular, na fase inicial do estabelecimento das mudas no campo. Nesse estudo foram investigados os efeitos da fertilização fosfatada em plantas jovens de $O$. pyramidale submetidas a dois ambientes de luz (alta e baixa irradiância), buscando-se responder às 
seguintes questões: (i) Quais serão os efeitos da fertilização fosfatada sobre o processo fotossintético, crescimento, acúmulo e alocação de massa seca de plantas jovens de O. pyramidale? (ii) Quais serão os efeitos da interação entre a fertilização e a disponibilidade de luz sobre o crescimento e as variáveis correlatas para esta espécie? As informações obtidas nesse estudo serão úteis para consolidar conhecimentos ecofisiológicos da O. pyramidale, visando ao aperfeiçoamento das técnicas silviculturais inerentes aos plantios florestais dessa espécie.

\section{MATERIAL E MÉTODOS}

\section{Área de estudo e condução do experimento}

O experimento foi conduzido em regime de casa de vegetação do Laboratório de Fisiologia e Bioquímica vegetal (LFBV) do Instituto Nacional de Pesquisas da Amazônia (MCTI-INPA). As sementes de Ochroma pyramidale (Cav. Ex Lamb.) Urb.) utilizadas no experimento foram coletadas nas regiões de Brasiléia e Xapuri, estado do Acre, Brasil. A quebra da dormência das sementes foi realizada de acordo com a metodologia proposta por Barbosa et al. (2004). As sementes foram postas para germinar em gerbox plástico contendo papel toalha embebido com água e, depois foram acondicionadas em câmaras de germinação, programadas para funcionar a temperatura de $30^{\circ} \mathrm{C}$ e com fotoperíodo de $12 \mathrm{~h}$ de iluminação em lâmpadas OSRAM $20 \mathrm{w}$ (com $75 \mu \mathrm{mol} \mathrm{m}^{-2} \mathrm{~s}^{-1}$ de irradiância, gerada por lâmpadas fluorescentes tubulares tipo luz do dia) e $12 \mathrm{~h}$ de escuro.

Após a germinação, com as radículas medindo cerca de $4 \mathrm{~cm}$, as plântulas foram transferidas para bandejas plásticas contendo vermiculita, onde permaneceram durante trinta dias, até serem transplantadas para sacos de $5 \mathrm{~L}$ contendo vermiculita expandida.

Para a instalação do experimento, um total de 40 plantas jovens de O. pyramidale (mudas) foi selecionado de acordo com a uniformidade de altura, o número de folhas e bom estado fitossanitário foliar (verificando-se ausência de patógenos, necroses ou cloroses aparentes) a partir de então, as mudas foram distribuídas em 4 tratamentos (com 10 indivíduos por tratamento, representando 10 repetições) para atender a proposição experimental de investigar plantas jovens de O. pyramidale submetidas a alta ou a baixa irradiância, na presença ou na ausência da fertilização fosfatada. As plantas jovens de $O$. pyramidale submetidas à baixa irradiância cresceram sob sombreamento que mantinha quantidade de luz da ordem de 10 a $15 \mu$ mol fótons $\mathrm{m}^{-2} \mathrm{~s}^{-1} \mathrm{e}$ as demais mudas foram mantidas em ambiente de alta irradiância com 1200 a $1400 \mu \mathrm{mol}$ fótons $\mathrm{m}^{-2} \mathrm{~s}^{-1}$. Esses valores de irradiância representam médias de 10 (dez) medidas pontuais para cada ambiente realizadas sempre no período de maior irradiância do dia (entre 11 e 13 horas), evitando-se dias com nebulosidade, determinando-se a irradiância por meio de sensores de luz (MQS-B sensor/ ULM-500 logger, Heinz Walz, Germany) a cada intervalo de duas semanas ao longo de todo período experimental até completar os 160 dias.

No experimento foram utilizadas duas soluções nutritivas a partir de modificações na solução base de Hoagland e Arnon (1950): 1) Solução + $\mathrm{KH}_{2} \mathbf{P O}_{4}: \mathrm{MgSO}_{4} 7 \mathrm{H}_{2} \mathrm{O}(2 \mathrm{mM}) ; \mathrm{KH}_{2} \mathrm{PO}_{4}(1 \mathrm{mM})$; $\mathrm{CaSO}_{4} 2 \mathrm{H}_{2} \mathrm{O}(2 \mathrm{mM}) ; \mathrm{K}_{2} \mathrm{SO}_{4}(2 \mathrm{mM}) ; \mathrm{H}_{3} \mathrm{BO}_{3}(0,46 \mathrm{mM}) ; \mathrm{MnCl}_{2} 4 \mathrm{H}_{2} \mathrm{O}(9,1 \mathrm{mM}) ; \mathrm{ZnSO}_{4} 7 \mathrm{H}_{2} \mathrm{O}$ (7,65 mM); CuSO4. $5 \mathrm{H}_{2} \mathrm{O}(3,2 \mathrm{mM}) ; \mathrm{H}_{2} \mathrm{MoO}_{4}(0,56 \mathrm{mM})$. O P foi fornecido como fosfato de potássio monobásico (1mM). 2) Solução - $\mathrm{KH}_{2} \mathrm{PO}_{4:} \mathrm{MgSO}_{4} 7 \mathrm{H}_{2} \mathrm{O}(2 \mathrm{mM}) ; \mathrm{CaSO}_{4} 2 \mathrm{H}_{2} \mathrm{O}(2 \mathrm{mM}) ; \mathrm{K}_{2}$ $\mathrm{SO}_{4}(2 \mathrm{mM}) ; \mathrm{H}_{3} \mathrm{BO}_{3}(0,46 \mathrm{mM}) ; \mathrm{MnCl}_{2 .} 4 \mathrm{H}_{2} \mathrm{O}(9,1 \mathrm{mM}) ; \mathrm{ZnSO}_{4} 7 \mathrm{H}_{2} \mathrm{O}(7,65 \mathrm{mM}) ; \mathrm{CuSO} 4.5 \mathrm{H}_{2} \mathrm{O}$ $(3,2 \mathrm{mM}) ; \mathrm{H}_{2} \mathrm{MoO}_{4}(0,56 \mathrm{mM})$.

Logo após a transferência das plântulas para os sacos plásticos, foram realizadas aplicações com solução nutritiva $1 / 5$ de força e conforme a resposta de crescimento da planta, a solução foi trocada para 1/3, para meia força (intervalos de aproximadamente um mês) e, por último, mantidas com a solução completa (últimos dois meses de experimentação), sendo aplicados $100 \mathrm{ml}$ de solução por planta, contendo os macro e micronutrientes, duas vezes por semana. Estas aplicações também serviam para manter a condição hídrica dos indivíduos, além de conservar as pesagens originais do conjunto (planta + substrato).

\section{Análise de Crescimento e acúmulo e alocação de biomassa}

As medidas biométricas de altura e diâmetro do coleto foram realizadas a cada 20 dias ao longo de todo o período experimental, durante 160 dias, totalizando nove medições. As medidas da altura 
total das plantas foram feitas com régua milimetrada, e as medidas do diâmetro à altura do coleto, utilizando-se paquímetro digital (Mitutoyo - CD-8" CX-B). As taxas de crescimento absoluto (TCA) e relativo (TCR) em altura e diâmetro, foram calculadas de acordo com metodologias descritas por Bugbee (1996). A área foliar (AF) foi determinada por meio de imagens digitalizadas em scanner de mesa e processadas no software Image J 1.47t (WIKA et al., 2007). A área foliar específica (AFE) foi calculada a partir da razão entre a área foliar e a massa foliar de discos foliares de área conhecida $\left(0,283 \mathrm{~cm}^{2}\right)$, sendo utilizados 5 discos por planta (EVANS; POORTER, 2001; POORTER et al. 2012). Ao final do experimento, as plantas foram subdivididas em folhas, caule e raiz, e acondicionadas em sacos de papel para secagem em estufa a $65^{\circ} \mathrm{C}$ até a obtenção de massa constante. A partir do material seco foram obtidas a massa seca foliar (MSF), massa seca caulinar (MSC), massa seca de raízes (MSR) e massa seca total (MST), e também foram calculadas as razões raiz/parte aérea (raiz $\left.\mathrm{PA}^{-1}\right)$, fração de massa foliar $\left(\mathrm{FMF}=\mathrm{MSF} \mathrm{MST}^{-1}\right)$, fração de massa caulinar $\left(\mathrm{FMC}=\mathrm{MSC} \mathrm{MST}^{-1}\right) \mathrm{e}$ fração de massa radicular $\left(\mathrm{FMR}=\mathrm{MSR} \mathrm{MST}^{-1}\right)$.

\section{Teores de nutrientes foliares}

Os teores de macro e micronutrientes foliares foram determinados em folhas maduras e completamente expandidas e realizadas após a conclusão do experimento. As amostras foram secas em estufa a $65^{\circ} \mathrm{C}$ até obtenção de massa constante. O nitrogênio total foi determinado por titulação (Kjeldahl) após digestão com ácido sulfúrico (MIYAZAWA et al., 1999). Os teores de fósforo foram determinados em amostras submetidas à digestão nitro-perclórica e determinados por espectrofotometria do visível a $725 \mathrm{~nm}$ conforme descrito por Vitti e Ferreira (1997). No mesmo extrato submetido à digestão nitro-perclórico, os teores dos demais nutrientes ( $\mathrm{Ca}, \mathrm{Mg}, \mathrm{K}, \mathrm{Fe}, \mathrm{Zn}$ e $\mathrm{Mn}$ ) foram determinados por espectrometria de absorção atômica (Perkin Elmer 1100B, Uberlingen, Alemanha).

\section{Fluorescência da clorofila}

As análises de fluorescência da clorofila $a$ foram realizadas em folhas selecionadas seguindo os mesmos critérios para as medições anteriores. Para tanto, utilizou-se um fluorômetro portátil (PEA, MK2 - 9600 - Hansatech, Norfolk, UK) e as análises foram realizadas entre 06:00 e 8:00 h. As folhas foram aclimatadas ao escuro durante 30 minutos e, em seguida, foram submetidas a um pulso de luz saturante de intensidade de $3000 \mu \mathrm{mol} \mathrm{m}^{-2} \mathrm{~s}^{-1}$ e comprimento de onda de $650 \mathrm{~nm}$ por 1 segundo. Os parâmetros de eficiência máxima do fotossistema II $\mathrm{F}_{\mathrm{v}} / \mathrm{F}_{\mathrm{m}}$ e os índices de desempenho $\mathrm{PI}_{\mathrm{ABS}}$ e PI $\mathrm{T}_{\text {TOTAL, }}$ provenientes da curva OJIP, foram calculados conforme Strasser et al. $(2004,2010)$.

\section{Determinação das trocas gasosas foliares}

As trocas gasosas foram realizadas ao final do experimento em folhas maduras, completamente expandidas e em bom estado fitossanitário no período entre 08:00 e 12:00 h. A partir de curvas de resposta da fotossíntese à irradiância $\left(\mathrm{P}_{\mathrm{N}} \mathrm{I}\right)$.foram determinadas a fotossíntese líquida $\left(\mathrm{P}_{\mathrm{N}}\right)$, condutância estomática (gs), transpiração (E) e a respiração no escuro (Rd), utilizando-se um analisador de gás a infravermelho (IRGA) portátil, de sistema aberto, modelo LI 6400 (Li- Cor, USA) equipado com fonte de luz artificial 6400-02B Red Blue. O IRGA foi ajustado para trabalhar com fluxo de ar de $400 \mu \mathrm{mol} \mathrm{s}{ }^{-1}$, temperatura da folha de $31^{\circ} \mathrm{C} \pm 1^{\circ} \mathrm{C}$ e concentrações de $\mathrm{CO}_{2}$ e $\mathrm{H}_{2} \mathrm{O}$ dentro da câmara de medição em torno de $400 \pm 1 \mu \mathrm{mol} \mathrm{mol}^{-1} \mathrm{e} 21 \pm 1 \mathrm{mmol} \mathrm{mol}^{-1}$, respectivamente. A partir das curvas de resposta fotossintética à irradiância $\left(\mathrm{P}_{\mathrm{N}}-\mathrm{I}\right)$ foram estimadas a fotossíntese líquida máxima $\left(P_{N \max }\right)$ e o rendimento quântico aparente $(\varphi)$. As curvas $\mathrm{P}_{\mathrm{N}}-\mathrm{I}$ foram processadas considerando uma densidade de fluxo de fótons (PPFD) entre 0 e $2000 \mu \mathrm{mol} \mathrm{m}^{-2} \mathrm{~s}^{-1}(0,25,50,75,100,250,500,750$, $1000,1500,2000)$ em escala decrescente. O modelo exponencial foi usado para ajustar à curva de resposta fotossintética a intensidade luminosa para cada planta (SANTOS JR. et al., 2013).

\section{Delineamento experimental e análise estatística}

O delineamento experimental utilizado foi o inteiramente casualizado (DIC), em esquema fatorial de 2x2, com dez repetições $(n=40)$. Os fatores foram: (i) 2 níveis de irradiância (alta irradiância 
e baixa irradiância) e (ii) 2 níveis de fósforo (0 e 1 mM). Os dados obtidos foram submetidos aos testes Kolmogorov-Sminorv e Levene para verificação da normalidade e homogeneidade de variâncias, respectivamente. Em seguida, foram submetidos à análise de variância (ANOVA) e as médias foram comparadas pelo teste de Duncan $(p<0,05)$. Todas as análises foram processadas utilizando-se o software Statistica 7.0 (StatSoft Inc., 2004).

\section{RESULTADOS E DISCUSSÃO}

O maior crescimento em altura e diâmetro foi observado nas plantas fertilizadas com fósforo e submetidas à alta irradiância (Figura $1 \mathrm{~A}-\mathrm{B}$ ). As plantas fertilizadas com $\mathrm{P}$ começaram a exibir diferenças das plantas sem $\mathrm{P}$ a partir de 20 e 60 dias de experimento, nos tratamentos submetidos as baixa e alta irradiâncias, respectivamente (Figura 1A). Em contraste, as diferenças em diâmetro somente foram observadas a partir do $80^{\circ}$ dia de experimento (Figura 1B). As diferenças de crescimento em altura e diâmetro entre plantas fertilizadas a pleno sol com plantas fertilizadas com P e submetidas a sombreamento foram observadas aos 80 e 100 dias de experimento, respectivamente (Figura 1A-B). Ao final do experimento, plantas fertilizadas com $\mathrm{P}$ submetidas à alta irradiância exibiram valores de altura e diâmetro 24 e 73\% maiores que as plantas com P sob baixa irradiância, respectivamente (Figura 1A-B). As diferenças foram mais marcantes entre os tratamentos de fósforo nos quais as plantas fertilizadas com P exibiram valores de altura e diâmetro 327 e 485\% maiores que as plantas sem P sob alta irradiância e 296 e 228\% maiores sob baixa irradiância, respectivamente (Figura $1 \mathrm{~A}-\mathrm{B})$.

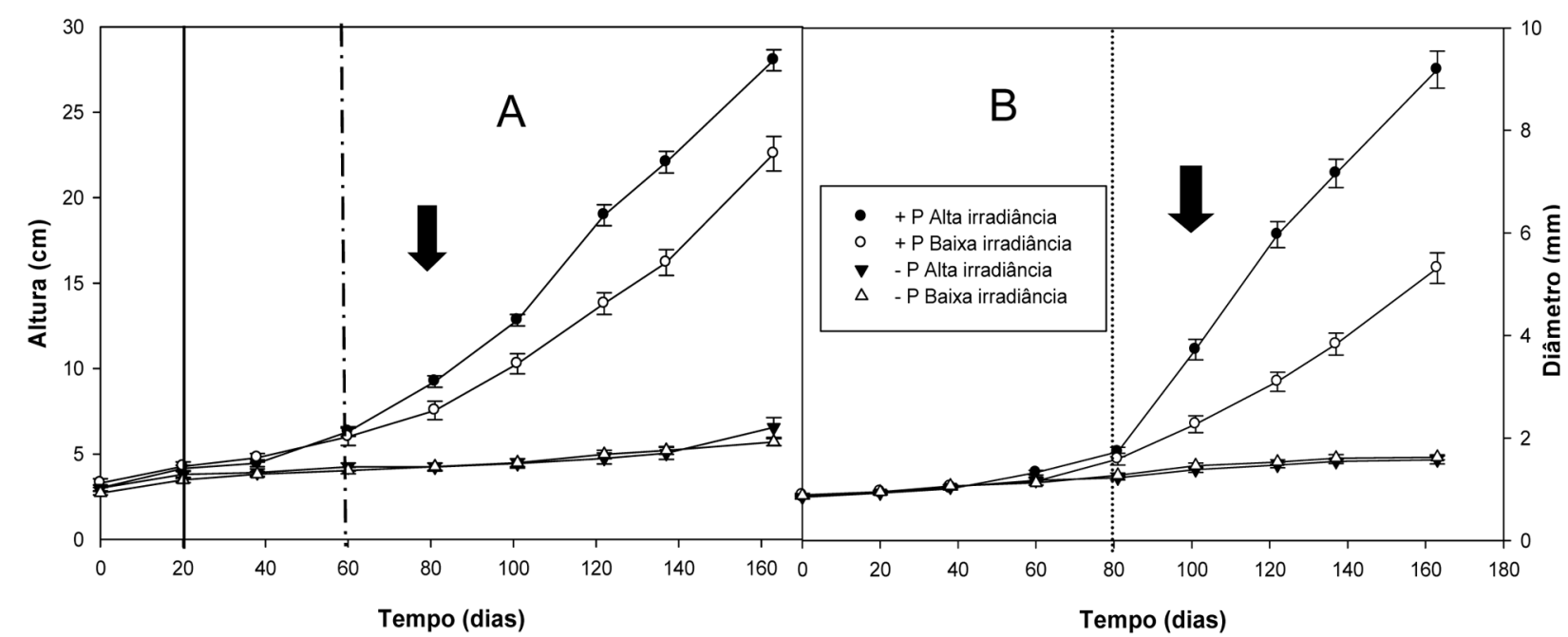

Figura 1. Crescimento em altura $(\mathrm{cm})$ e diâmetro $(\mathrm{mm})$ de plantas jovens de Ochroma pyramidale em resposta aos tratamentos de fertilização fosfatada e a ambientes contrastantes de irradiância, durante 160 dias. Linha tracejada: tempo em que o tratamento (+P alta irradiância) se diferenciou do tratamento (-P alta irradiância); seta preta: tempo em que o tratamento ( $P$ alta irradiância) se diferenciou do tratamento ( $+P$ baixa irradiância); Linha pontilhada: tempo em que os tratamentos (+P alta irradiância) e (+P baixa irradiância) se diferenciaram do tratamento (- $P$ alta irradiância) e (- $P$ baixa irradiância), respectivamente.

Figure 1. Growth in height $(\mathrm{cm})$ and diameter $(\mathrm{mm})$ of young plants of Ochroma pyramidale in response to the treatments of $P$ fertilization and contrasting irradiance environments, during 160 days. Dashed line: Time at which treatment (+ P high irradiance) differed from treatment (-P high irradiance); black arrow: time at which treatment $(+\mathrm{P}$ high irradiance) differed from the treatment ( $\mathrm{P}$ low irradiance); dotted line: time at which treatments $(+\mathrm{P}$ high irradiance) and $(+\mathrm{P}$ low irradiance) differed from treatment $(-\mathrm{P}$ high irradiance) and (-P low irradiance), respectively.

A fertilização com P promoveu as maiores taxas de crescimento absoluto e relativo em ambos os ambientes de irradiância, com destaque para as plantas sob alta irradiância (Tabela 1). As plantas fertilizadas com P e mantidas sob alta irradiância alcançaram valores de TCA-a e TCA-d 30 e $88 \%$ e, valores de TCR-a e TCR-d 14 e 33\% maiores que as plantas mantidas sob baixa irradiância, respectivamente (Tabela 1). 
Cunha et al. - Biomassa, trocas gasosas e aspectos nutricionais de plantas jovens de pau de balsa (Ochroma pyramidale

(Cav. Ex Lamb.) Urb.) submetidas à fertilização fosfatada em ambientes contrastantes de irradiância

Tabela 1. Crescimento absoluto em altura (TCA-a, $c m$ mês $\mathrm{s}^{-1}$ ) e diâmetro (TCA-d, mm mês $\mathrm{s}^{-1}$ ) e crescimento relativo em altura (TCR-a, $\mathrm{cm} \mathrm{cm}^{-1}$ mês $^{-1}$ ) e diâmetro (TCR-d, $\mathrm{mm} \mathrm{mm}^{-1} \mathrm{mês}^{-1}$ ) de plantas jovens de Ochroma pyramidale sob fertilização fosfatada em ambientes contrastantes de irradiância.

Table 1. Absolute Height Growth Rate (AGR $-\mathrm{h})\left(\mathrm{cm}^{\left.-10 n \mathrm{th}^{-1}\right)}\right.$ and diameter (AGR-d) (mm month $\left.{ }^{-1}\right)$ and Relative Height and Diameter Growth Rates $\left(\mathrm{cm} \mathrm{cm}^{-1} \mathrm{month}^{-1}\right.$ and $\left.\mathrm{mm} \mathrm{mm}^{-1} \mathrm{month}^{-1}\right)$ of young plants of Ochroma pyramidale under $\mathrm{P}$ fertilization in contrasting irradiance environments.

\begin{tabular}{lcc|cc}
\hline & \multicolumn{2}{c|}{ Alta irradiância } & \multicolumn{2}{c}{ Baixa irradiância } \\
\hline TCA-a & $\mathbf{- P}$ & $\mathbf{+ P}$ & $\mathbf{- P}$ & $\mathbf{+ P}$ \\
TCA-d & $0,68 \pm 0,12 \mathrm{Ab}$ & $4,61 \pm 0,12 \mathrm{Aa}$ & $0,54 \pm 0,04 \mathrm{Ab}$ & $3,55 \pm 0,17 \mathrm{Ba}$ \\
TCR-a & $0,13 \pm 0,04 \mathrm{Ab}$ & $1,54 \pm 0,07 \mathrm{Aa}$ & $0,13 \pm 0,01 \mathrm{Ab}$ & $0,82 \pm 0,06 \mathrm{Ba}$ \\
TCR-d & $0,15 \pm 0,02 \mathrm{Ab}$ & $0,41 \pm 0,01 \mathrm{Aa}$ & $0,13 \pm 0,01 \mathrm{Ab}$ & $0,36 \pm 0,01 \mathrm{Ba}$ \\
\hline
\end{tabular}

Média \pm erro padrão. Médias seguidas da mesma letra maiúscula entre ambientes de irradiância diferentes, e minúsculas entre tratamentos de fertilização $(-P ;+P)$ não diferem estatisticamente ( $p>0,05$; Teste Duncan).

No ambiente de baixa irradiância, a ausência de fósforo limitou a área foliar total (AFT), tamanho médio foliar (TMF) e número de folhas (NF) de O. pyramidale em 99, 95 e 83\%, quando comparadas estas variáveis das plantas fertilizadas com $\mathrm{P}$, no ambiente de alta irradiância, as diferenças foram de 98, 93 e 77\%, respectivamente (Tabela 2). Nas plantas fertilizadas com $\mathrm{P}$, o ambiente lumínico influenciou na área foliar e número de folhas, no qual plantas sob alta irradiância exibiram valores de AFT e TMF 21 e 38\% maiores e número de folhas 10\% menores que as plantas sob baixa irradiância. Quanto à área foliar específica as plantas de sombra exibiram os maiores valores comparadas com as plantas sob alta irradiância (Tabela 2).

Tabela 2. Área foliar total (AFT), tamanho médio foliar (TMF), número de folhas e área foliar específica (AFE) de plantas jovens de Ochroma pyramidale submetidas à fertilização fosfatada em ambientes contrastantes de irradiância.

Table 2. Total Leaf Area, Average Leaf Size, Number of leaflets and Specific Leaf Area (SLA) of young plants of Ochroma pyramidale under $\mathrm{P}$ fertilization in contrasting irradiance environments.

\begin{tabular}{lcc|cc}
\hline & \multicolumn{2}{c|}{ Alta irradiância } & \multicolumn{2}{c}{ Baixa irradiância } \\
\hline & $-\mathbf{P}$ & $\mathbf{+}$ & $-\mathbf{P}$ & $\mathbf{P}$ \\
\hline $\mathrm{AFT}\left(\mathrm{cm}^{2}\right)$ & $14 \pm 5 \mathrm{Ab}$ & $1212 \pm 35 \mathrm{Aa}$ & $16 \pm 3 \mathrm{Ab}$ & $1001 \pm 111 \mathrm{Ba}$ \\
$\mathrm{TMF}\left(\mathrm{cm}^{2}\right)$ & $8 \pm 2 \mathrm{Ab}$ & $148 \pm 6 \mathrm{Aa}$ & $7 \pm 1 \mathrm{Ab}$ & $107 \pm 9 \mathrm{Ba}$ \\
No folhas $(\mathrm{NF})$ & $1,4 \pm 0,24 \mathrm{Ab}$ & $8,3 \pm 0,37 \mathrm{Ba}$ & $2,1 \pm 0,31 \mathrm{Ab}$ & $9,2 \pm 0,29 \mathrm{Aa}$ \\
$\mathrm{AFE}\left(\mathrm{cm}^{2} \mathrm{~g}^{-1}\right)$ & $203 \pm 15 \mathrm{Bb}$ & $271 \pm 8 \mathrm{Ba}$ & $357 \pm 17 \mathrm{Ab}$ & $787 \pm 11 \mathrm{Aa}$ \\
\hline
\end{tabular}

Média \pm erro padrão. Médias seguidas da mesma letra maiúscula entre ambientes de irradiância diferentes, e minúsculas entre tratamentos de fertilização (-P; $+P)$ não diferem estatisticamente $(p>0,05$; Teste Duncan).

Em relação à massa seca, tanto a fertilização fosfatada quanto a irradiância contribuíram para o aumento da biomassa nas raízes e na parte aérea das plantas (Tabela 3). Sendo que, a irradiância influenciou maior alocação de massa seca na fração radicular, sob alta irradiância, enquanto que, as plantas sob baixa irradiância investiram mais na fração de massa foliar (Tabela 3).

Tabela 3. Massa seca foliar (MSF), caulinar (MSC), radicular (MSR), total (MST) e fração de massa foliar (FMF), caulinar (FMC), radicular (FMR) de plantas jovens de Ochroma pyramidale submetidas à fertilização fosfatada em ambientes contrastantes de irradiância.

Table 3. Leaf dry mass, Stem dry mass, Total dry mass, Leaf mass ratio, Stem mass ratio and Root mass ratio of young plants of Ochroma pyramidale under $\mathrm{P}$ fertilization in contrasting irradiance environments.

\begin{tabular}{lcccc}
\hline & \multicolumn{2}{c}{ Alta irradiância } & \multicolumn{2}{c}{ Baixa irradiância } \\
\hline & $\mathbf{- P}$ & $\mathbf{+ P}$ & $\mathbf{- P}$ & $\mathbf{+}$ \\
\hline MSF (g) & $0,11 \pm 0,02 \mathrm{Ab}$ & $6,3 \pm 0,29 \mathrm{Aa}$ & $0,07 \pm 0,01 \mathrm{Ab}$ & $1,8 \pm 0,26 \mathrm{Ba}$ \\
MSC (g) & $0,05 \pm 0,01 \mathrm{Ab}$ & $2,8 \pm 0,20 \mathrm{Aa}$ & $0,03 \pm 0,002 \mathrm{Ab}$ & $0,45 \pm 0,06 \mathrm{Ba}$ \\
MSR(g) & $0,07 \pm 0,02 \mathrm{Ab}$ & $5,38 \pm 0,41 \mathrm{Aa}$ & $0,04 \pm 0,003 \mathrm{Aa}$ & $0,68 \pm 0,10 \mathrm{Ba}$ \\
MST (g) & $0,23 \pm 0,05 \mathrm{Ab}$ & $14,5 \pm 0,78 \mathrm{Aa}$ & $0,14 \pm 0,003 \mathrm{Ab}$ & $3,0 \pm 0,41 \mathrm{Ba}$ \\
FMF $\left(\mathrm{g} \mathrm{g}^{-1}\right)$ & $0,46 \pm 0,03 \mathrm{Aa}$ & $0,44 \pm 0,01 \mathrm{Ba}$ & $0,52 \pm 0,02 \mathrm{Ab}$ & $0,63 \pm 0,01 \mathrm{Aa}$ \\
FMC $\left(\mathrm{g} \mathrm{g}^{-1}\right)$ & $0,23 \pm 0,02 \mathrm{Aa}$ & $0,19 \pm 0,01 \mathrm{Ab}$ & $0,21 \pm 0,01 \mathrm{Aa}$ & $0,15 \pm 0,005 \mathrm{Bb}$ \\
FMR $\left(\mathrm{g} \mathrm{g}^{-1}\right)$ & $0,31 \pm 0,02 \mathrm{Ab}$ & $0,37 \pm 0,01 \mathrm{Aa}$ & $0,27 \pm 0,01 \mathrm{Aa}$ & $0,22 \pm 0,01 \mathrm{Ba}$ \\
\hline
\end{tabular}

Médias seguidas da mesma letra maiúscula entre ambientes de irradiância diferentes, e minúsculas entre tratamentos de fertilização $(-P ;+P)$ não diferem estatisticamente ( $p>0,05$; Teste Duncan). 
Quanto aos teores de macronutrientes verificou-se que as plantas fertilizadas com P sob baixa irradiância exibiram os maiores valores (Tabela 4). Os teores de $\mathrm{N}$ variaram de 16 até $31 \mathrm{~g} \mathrm{~kg}^{-1}$, no qual as plantas fertilizadas com P sob baixa irradiância exibiram os maiores valores e as plantas não fertilizadas com P sob alta irradiância exibiram os menores valores (Tabela 4). Os teores de K foram 4,4 e 6,5 vezes maior nas plantas fertilizadas com P comparada com as plantas não fertilizadas com $\mathrm{P}$, sob alta e baixa irradiância, respectivamente (Tabela 4). Para os teores foliares de $\mathrm{P}$, as plantas fertilizadas com P exibiram valores 137 e 54\% superiores as plantas não fertilizadas com P, sob alta e baixa irradiância, respectivamente (Tabela 4). Para os cátions divalentes Ca e $\mathrm{Mg}$, a fertilização fosfatada e a baixa irradiância contribuíram para o maior teor foliar (Tabela 4).

Tabela 4. Teores foliares de macro e micronutrientes em plantas jovens de Ochroma pyramidale submetidas à fertilização fosfatada em ambientes contrastantes de irradiância.

Table 4. Leaf macro and micronutrients concentration in young plants of Ochroma pyramidale under phosphorus fertilization in contrasting irradiance environments.

\begin{tabular}{lcccc}
\hline & \multicolumn{2}{c}{ Alta irradiância } & \multicolumn{2}{c}{ Baixa irradiância } \\
\hline & $-\mathbf{P}$ & $\mathbf{+}$ & $\mathbf{P}$ & $\mathbf{P}$ \\
\hline $\mathrm{N}\left(\mathrm{g} \mathrm{kg}^{-1}\right)$ & $16,2 \pm 0,5 \mathrm{Aa}$ & $16,8 \pm 0,49 \mathrm{Ba}$ & $18,0 \pm 0,7 \mathrm{Ab}$ & $31,3 \pm 0,58 \mathrm{Aa}$ \\
$\mathrm{P}\left(\mathrm{g} \mathrm{kg}^{-1}\right)$ & $0,45 \pm 0,09 \mathrm{Bb}$ & $1,07 \pm 0,04 \mathrm{Ba}$ & $0,93 \pm 0,02 \mathrm{Ab}$ & $1,43 \pm 0,04 \mathrm{Aa}$ \\
$\mathrm{K}\left(\mathrm{g} \mathrm{kg}^{-1}\right)$ & $4,79 \pm 1,47 \mathrm{Ab}$ & $21,20 \pm 0,69 \mathrm{Ba}$ & $4,71 \pm 0,04 \mathrm{Ab}$ & $30,74 \pm 1,05 \mathrm{Aa}$ \\
$\mathrm{Ca}\left(\mathrm{g} \mathrm{kg}^{-1}\right)$ & $3,03 \pm 0,56 \mathrm{Bb}$ & $4,66 \pm 0,25 \mathrm{Ba}$ & $4,91 \pm 0,03 \mathrm{Ab}$ & $6,80 \pm 0,17 \mathrm{Aa}$ \\
$\mathrm{Mg}\left(\mathrm{g} \mathrm{kg}^{-1}\right)$ & $1,19 \pm 0,21 \mathrm{Ba}$ & $1,41 \pm 0,07 \mathrm{Ba}$ & $1,57 \pm 0,04 \mathrm{Ab}$ & $2,14 \pm 0,04 \mathrm{Aa}$ \\
$\mathrm{Fe}\left(\mathrm{mg} \mathrm{kg}^{-1}\right)$ & $368 \pm 35 \mathrm{Aa}$ & $138 \pm 21 \mathrm{Bb}$ & $411 \pm 8 \mathrm{Aa}$ & $363 \pm 18 \mathrm{Aa}$ \\
$\mathrm{Zn}\left(\mathrm{mg} \mathrm{kg}^{-1}\right)$ & $26,9 \pm 0,8 \mathrm{Bb}$ & $37,0 \pm 2,0 \mathrm{Aa}$ & $38,9 \pm 0,8 \mathrm{Aa}$ & $42,7 \pm 1,0 \mathrm{Aa}$ \\
$\mathrm{Mn}\left(\mathrm{mg} \mathrm{kg}^{-1}\right)$ & $94,3 \pm 17,3 \mathrm{Aa}$ & $103,7 \pm 10,9 \mathrm{Ba}$ & $98 \pm 1,2 \mathrm{Ab}$ & $209,7 \pm 8,1 \mathrm{Aa}$ \\
$\mathrm{Cu}\left(\mathrm{mg} \mathrm{kg}^{-1}\right)$ & $6,9 \pm 0,8 \mathrm{Aa}$ & $6,8 \pm 0,5 \mathrm{Aa}$ & $8,4 \pm 0,8 \mathrm{Aa}$ & $9,34 \pm 0,7 \mathrm{Aa}$ \\
\hline
\end{tabular}

Média \pm erro padrão. Médias seguidas da mesma letra maiúscula entre ambientes de irradiância diferentes, e minúsculas entre tratamentos de fertilização $(-P ;+P)$ não diferem estatisticamente $(p>0,05$; Teste Duncan).

A ausência de P promoveu redução na eficiência do transporte de elétrons, fato verificado pela comparação entre as plantas fertilizadas e não fertilizadas, nos dois ambientes de luz, a partir dos valores de $\mathrm{F}_{\mathrm{v}} / \mathrm{F}_{\mathrm{m}}, \mathrm{PI}_{\mathrm{ABS}}$ e PI $\mathrm{I}_{\text {total }}$ (Tabela 5). Entre as plantas que receberam fertilização fosfatada observouse que as plantas sob alta irradiância exibiram os maiores índices de desempenho, com valores de $\mathrm{PI}_{\mathrm{ABS}}$ e PI $\mathrm{I}_{\text {total }} 19$ e 96\% maiores que as plantas sob baixa irradiância, respectivamente (Tabela 5).

A resposta fotossintética foi influenciada pelo aumento da irradiância, com destaque para as plantas fertilizadas com fósforo e submetidas à alta irradiância (Figura 2).

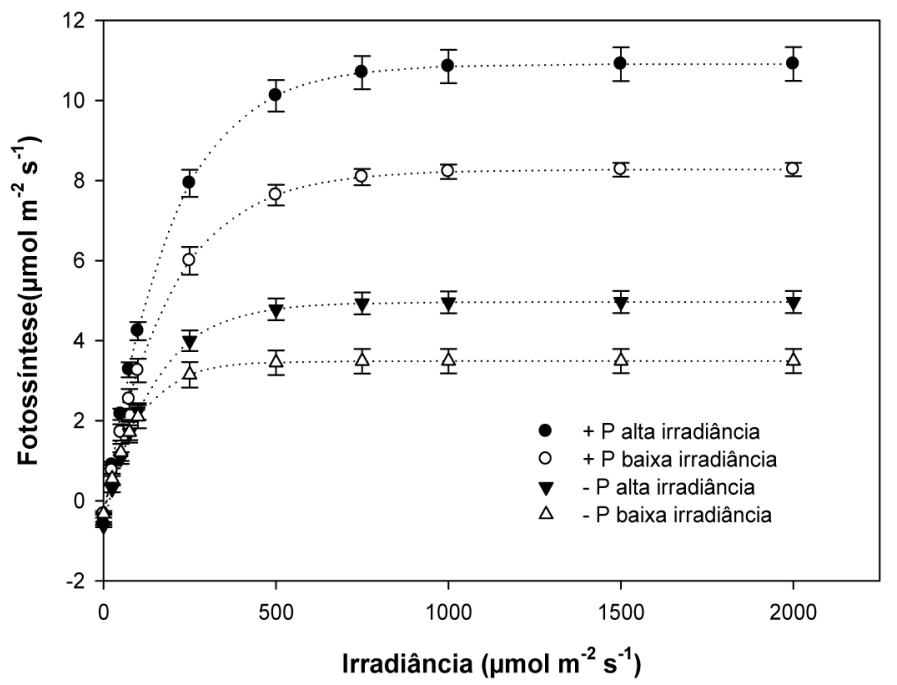

Figura 2. Curva de resposta fotossintética em função do aumento da irradiância em plantas jovens de Ochroma pyramidale submetidas à fertilização fosfatada em ambientes contrastantes de irradiância.

Figure 2. Photosynthetic response curve related to increasing irradiance of young plants of Ochroma pyramidale subjected to phosphorus fertilization in contrasting irradiance environments. 
A fotossíntese máxima das plantas fertilizadas com P foi 118 e 137\% maiores do que das plantas sem fertilização fosfatada, nos ambientes de sol e sombra, respectivamente (Tabela 5). A intensidade luminosa aumentou em 31 e 43\% a fotossíntese máxima, nas plantas fertilizadas e não fertilizadas, respectivamente (Tabela 5). O rendimento quântico respondeu ao efeito da fertilização somente nas plantas submetidas à alta irradiância, com valor 50\% maior quando comparadas às plantas não fertilizadas (Tabela 5). A semelhança da fotossíntese, as plantas sob alta irradiância exibiram maiores taxas de respiração do que as plantas sob baixa irradiância independente das condições de fertilização (Tabela 5). Quanto à condutância estomática, plantas fertilizadas com fósforo exibiram valores 2,7 vezes maiores do que as plantas não fertilizadas com fósforo, em ambos os ambientes (Tabela 5).

Tabela 5. Rendimento quântico máximo do fotossistema II $\left(\mathrm{F}_{\mathrm{v}} / \mathrm{F}_{\mathrm{m}}\right)$, índice de desempenho $\left(\mathrm{PI}_{\mathrm{ABS}}\right)$ e índice de desempenho total $\left(\mathrm{PI}_{\text {total }}\right)$, Fotossíntese máxima $\left(\mathrm{P}_{\mathrm{nmax}} ; \mu \mathrm{mol} \mathrm{m}^{-2} \mathrm{~s}^{-1}\right)$ rendimento quântico aparente $\left(\varphi ; \mathrm{mol} \mathrm{CO}_{2}\right.$

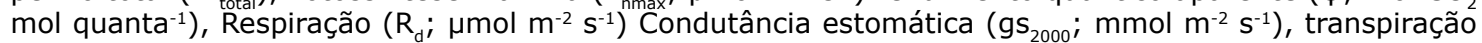
$\left(\mathrm{E}_{2000} ; \mathrm{mmol} \mathrm{m}^{-2} \mathrm{~s}^{-1}\right)$, de plantas jovens de Ochroma pyramidale submetidas à fertilização fosfatada em ambientes contrastantes de irradiância.

Table 5. Maximum quantum yield of photosystem II $\left(\mathrm{F}_{\mathrm{v}} / \mathrm{F}_{\mathrm{m}}\right)$ Performance index $\left(\mathrm{PI}_{\mathrm{ABS}}\right)$, Total performance index

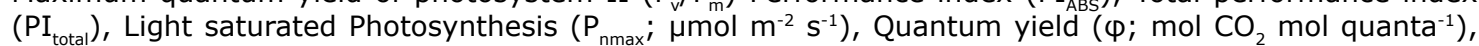

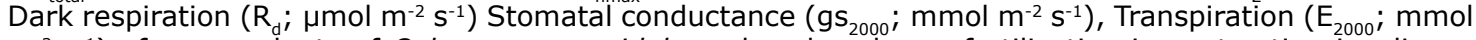
$\mathrm{m}^{-2} \mathrm{~s}^{-1}$ ) of young plants of Ochroma pyramidale under phosphorus fertilization in contrasting irradiance environments.

\begin{tabular}{lcc|cc}
\hline & \multicolumn{2}{c|}{ Alta irradiância } & \multicolumn{2}{c}{ Baixa irradiância } \\
\hline & $-\mathbf{P}$ & $\mathbf{+}$ & $\mathbf{P}$ & $\mathbf{+}$ \\
\hline $\mathrm{F}_{\mathrm{v}} / \mathrm{F}_{\mathrm{m}}$ & $0,77 \pm 0,018 \mathrm{Ab}$ & $0,84 \pm 0,002 \mathrm{Aa}$ & $0,78 \pm 0,020 \mathrm{Ab}$ & $0,85 \pm 0,001 \mathrm{Aa}$ \\
$\mathrm{PI}_{\mathrm{ABS}}$ & $0,93 \pm 0,14 \mathrm{Ab}$ & $2,17 \pm 0,09 \mathrm{Aa}$ & $0,97 \pm 0,07 \mathrm{Ab}$ & $1,83 \pm 0,03 \mathrm{Ba}$ \\
$\mathrm{PI}_{\text {total }}$ & $0,32 \pm 0,04 \mathrm{Ab}$ & $0,92 \pm 0,06 \mathrm{Aa}$ & $0,24 \pm 0,01 \mathrm{Ab}$ & $0,47 \pm 0,01 \mathrm{Ba}$ \\
$\mathrm{P}_{\mathrm{nmax}}$ & $5,0 \pm 0,3 \mathrm{Ab}$ & $10,9 \pm 0,4 \mathrm{Aa}$ & $3,5 \pm 0,3 \mathrm{Bb}$ & $8,3 \pm 0,2 \mathrm{Ba}$ \\
$\varphi$ & $0,041 \pm 0,004 \mathrm{Ab}$ & $0,063 \pm 0,004 \mathrm{Aa}$ & $0,040 \pm 0,007 \mathrm{Aa}$ & $0,047 \pm 0,005 \mathrm{Ba}$ \\
$\mathrm{R}_{\mathrm{d}}$ & $0,63 \pm 0,04 \mathrm{Aa}$ & $0,57 \pm 0,04 \mathrm{Aa}$ & $0,33 \pm 0,02 \mathrm{Ba}$ & $0,34 \pm 0,08 \mathrm{Ba}$ \\
$\mathrm{gs}_{2000}$ & $110 \pm 9 \mathrm{Ab}$ & $301 \pm 19 \mathrm{Aa}$ & $97 \pm 15 \mathrm{Ab}$ & $265 \pm 14 \mathrm{Aa}$ \\
$\mathrm{E}_{2000}$ & $3,0 \pm 0,3 \mathrm{Ab}$ & $5,7 \pm 0,3 \mathrm{Aa}$ & $2,4 \pm 0,3 \mathrm{Ab}$ & $5,2 \pm 0,3 \mathrm{Aa}$ \\
\hline
\end{tabular}

Média \pm erro padrão. Médias seguidas da mesma letra maiúscula entre ambientes de irradiância diferentes, e minúsculas entre tratamentos de fertilização $(-P ;+P)$ não diferem estatisticamente ( $p>0,05$; Teste Duncan).

As condições limitantes de P e de irradiância (baixa) reduziram significativamente o metabolismo do carbono, o crescimento e o acúmulo de massa seca de O. pyramidale. A limitação de P afeta o metabolismo e crescimento vegetal devido à essencialidade e função deste elemento nas plantas, uma vez que é um dos principais componentes dos ácidos nucléicos, açúcares fosfatados, ATP e fosfolipídios, e por exercer papel importante na fotossíntese e no metabolismo energético como um todo (REICH et al., 2009; BLOOMFIELD et al., 2014). Assim, o menor crescimento e acúmulo de massa seca sob limitação de P são resultantes tanto da restrição da área foliar quanto da redução da fotossíntese. Devido ao papel central do P, pesquisas têm demonstrado que espécies arbóreas tropicais respondem positivamente ao aumento na dosagem de $\mathrm{Pe}$, em grande medida, isto se deve as baixas concentrações de P nos solos tropicais (SANTOS et al., 2008; FERNANDES et al., 2013).

Quanto ao ambiente de irradiância, as plantas de O. pyramidale responderam melhor, em termos de crescimento e ganho de biomassa, aos ambientes com alta irradiância, aspecto que, possivelmente, esteja relacionado ao fato de $O$. pyramidale ser classificada como pioneira de crescimento rápido (MIDGLEY et al., 2010), mas em termos funcionais, este resultado sugere robustez na maquinaria fotossintética para captura de energia e eficiência na conversão da mesma em fotoassimilados. Alguns autores também têm empregado parâmetros como índices de plasticidade fenotípica (IPF) para consubstanciar essas respostas com tratamentos contrastantes, devido à capacidade da relação entre variáveis captura melhor as respostas entre os maiores e menores valores obtidos como resultados dos tratamentos (VALLADARES et al., 2000; LIMA et al., 2010).

Sob condições contrastantes de nutrientes e irradiância as plantas também tendem a exibir mudanças na arquitetura e alocação de massa seca entre os diferentes órgãos, no intuito de aperfeiçoar a captação e utilização desses recursos primários (GLEASON et al., 2011; POORTER et al., 2012). Assim, em condições de alta irradiância, há uma tendência de maior investimento em biomassa radicular ao passo que sob baixa irradiância as plantas tendem a investir mais em biomassa foliar. 
Esse comportamento foi observado nas plantas jovens de O. pyramidale, em especial sob condições não limitantes de P. Os maiores valores de FMR nas plantas sob alta irradiância favorece maior absorção de água e nutrientes, em condições onde a água torna-se menos disponível ao sistema radicular, devido a maiores taxas de evaporação do substrato (CARVALHO et al., 2006). Por outro lado, o maior valor de FMF nas plantas de sombra ocorre devido à necessidade de expandir a área foliar, proporcionando aumento da área de captação de irradiância para os processos fotossintéticos, uma vez que nesses ambientes a luz é um fator limitante (LIMA et al., 2008).

Sob alta irradiância, as plantas fertilizadas com P exibiram maior alocação de biomassa para raiz. Estudos relacionados aos efeitos do investimento em fração de massa radicular com a disponibilidade de fósforo são conflitantes, uma vez que alguns estudos verificaram pequena inibição do crescimento da raiz, podendo até mesmo haver aumento da fração radicular, sob deficiência de fósforo, aspecto que, potencialmente, ampliaria a superfície de absorção de nutrientes e poderia funcionar como uma estratégia para sobrevivência de algumas espécies que crescem sob baixa disponibilidade de fósforo no solo (WARREN, 2011, SINGH et al., 2013), enquanto que outros estudos observaram investimento na biomassa radicular com a fertilização fosfatada (SANTOS et al., 2008; CHENG et al., 2014). A área foliar total e o número de folhas foram bastante limitados pela insuficiência de fósforo. Os mecanismos dessas respostas parecem estar relacionados ao papel do fósforo inorgânco (Pi) em contribuir na produção de folhas e na expansão foliar, processos relacionados à divisão celular (FREDEEN, 1988), uma vez que o fósforo desempenha papel importante na atividade de divisão celular (SANO et al., 1999). Essas evidências, de certa forma, demonstram a transversalidade funcional do P na estruturação de novos tecidos a partir da divisão celular e na estrutura e função das membranas celulares (KAVANOVÁ et al., 2006), aspectos que também podem ter concorrido para o melhor desempenho das plantas de O. pyramidale fertilizadas com $\mathrm{P}$, sob alta irradiância, face as maiores taxas de fotossíntese e produção de biomassa verificadas nestes tratamentos. A área foliar específica (AFE) foi maior nas plantas de sombra, em ambos os tratamentos de fertilização. A AFE reflete a área disponível para captura de luz por unidade de fotoassimilados investidos na folha (EVANS; POORTER, 2001), sendo que altos valores tem sido associado à alta capacidade competitiva por luz em termos de fotossíntese na base da massa (DAHLGREN et al., 2006) e a menores investimentos na lignificação dos tecidos, fato comum em plantas em condição de sombreamento (PEREIRA et al., 2009; ROSSATO et al., 2010). A AFE foi maior nas plantas fertilizadas com P, provavelmente, devido ao aumento na área foliar total, sendo que o aumento na espessura da folha está associado a maior alocação de biomassa para componentes estruturais do que metabólicos (REICH et al., 1991; SARDANS et al., 2006).

Quanto aos nutrientes foliares, observou-se que os teores de macronutrientes foram maiores nas plantas de sombra, em ambos os tratamentos de fertilização, com exceção dos teores de $\mathrm{N}$ e K que foram maiores na sombra somente quando fertilizadas com fósforo. A concentração de nutrientes foliares em ambientes contrastantes de luminosidade parece depender da espécie, podendo apresentar maiores valores nas plantas com menor irradiância, como para P em Cedrela odorata (GYMAH; NAKAO, 2007), ou mesmo apresentando maiores valores em plantas sob alta irradiância, como observado para N, K, Fe, Mn em mudas de Swietenia macrophylla (GONÇALVES et al., 2005), ou não apresentando diferenças entre os ambientes lumínicos (RONQUIM et al., 2009; ROSSATO et al., 2010).

Em estudo com plantas jovens de espécies tropicais foi observado redução acentuada de fósforo foliar no tratamento com remoção do fósforo da solução nutritiva, no entanto, não foi encontrado efeito da ausência de P no teor de N foliar (BLOOMFIELD et al., 2014). Nesse mesmo estudo verificou-se maior alocação de $\mathrm{N}$ para moléculas de clorofila e a eficiência fotossintética no uso do $\mathrm{N}\left(\mathrm{EF}_{\mathrm{N}}\right)$ foi significativamente reduzida em plantas com baixo-P. Estes autores afirmam que baixo-P no solo pode alterar as relações fotossíntese-nitrogênio em árvores tropicais (BLOOMFIELD et al., 2014).

Quantos aos cátions, uma relação positiva entre teores de fósforo e potássio foi verificada. Em plantas de Swietenia macrophylla verificou-se relação linear e positiva entre a adubação fosfatada e a absorção de potássio pelas plantas (SANTOS et al., 2008). Também foi observado resposta positiva entre fósforo e magnésio nas plantas de sombra. Um dos principais papéis do magnésio é de ser co-fator de muitas enzimas fosforilativas, formando uma ponte entre o pirofosfato do ATP ou ADP (tri e difosfato de adenosina) e a molécula da enzima (MAATHUIS, 2009). Adicionalmente, observou-se relação positiva entre fósforo foliar e os teores de cálcio em ambos os ambientes. Uma 
das importantes funções do cálcio está associada à manutenção da estabilidade de membrana, que é fundamental para a manutenção das cadeias transportadoras de elétrons e, por conseguinte, das atividades fosforilativas (MAATHUIS, 2009).

Com relação aos parâmetros da fluorescência da clorofila $a$, a limitação de fósforo reduziu significativamente a eficiência fotoquímica do fotossistema II $\left(\mathrm{F}_{\mathrm{v}} / \mathrm{F}_{\mathrm{m}}\right) \mathrm{em}$ ambos os níveis de irradiância. Plantas sob deficiência nutricional têm mostrado reduções na eficiência no uso da luz, especialmente, sob deficiência de P (GYMAH; NAKAO, 2007; SINGH et al., 2013). O fato é que concentrações adequadas de $\mathrm{P}$ são determinantes para manter o status energético celular e o potencial de membrana, em particular, que implica gasto de energia (ATP), sabendo-se que a natureza das biomembranas exige este gasto energético, originário tanto dos produtos da fotossíntese quanto do processo respiratório. Por outro lado, foi recentemente verificado que a deficiência de fósforo pode promover diferentes danos celulares de origem fotooxidativa nas membranas (HERNÁNDEZ; MUNNÉ-BOSCH, 2015).

$\mathrm{O}$ índice de desempenho $\left(\mathrm{PI}_{\mathrm{ABS}}\right)$ permite análise mais ampla do processo de funcionamento do aparato fotossintético e tem sido considerado como um parâmetro mais sensível para a detecção e quantificação de estresse em plantas do que a resposta da eficiência máxima do fotossistema II $\left(\mathrm{F}_{\mathrm{v}} / \mathrm{F}_{\mathrm{m}}\right)$ (GONÇALVES; SANTOS JR., 2005). Isso porque esse parâmetro relaciona a eficiência de absorção, captura e transferência de energia de excitação pelo fotossistema II proporcionando melhor diagnóstico do grau de efeito do ambiente estressante. O PI ${ }_{\text {total }}$ o índice de desempenho para a conservação de energia proveniente da absorção de fótons pelo PSII para o fluxo de redução dos receptores finais de elétrons do PSI (DESOTGIU et al., 2012). As reduções da eficiência fotoquímica e dos índices de desempenho nas plantas sob deficiência de fósforo podem estar relacionadas às perdas de estabilidade e integridade das membranas dos tilacóides, uma vez que a deficiência de P compromete a formação de fosfolipídios de membranas (OOSTERHUIS et al., 2008). Por outro lado, plantas fertilizadas com fósforo aumentam o desempenho do fotossistema II como resultado de maior número de centros de reação e que este fotossistema transporta energia de forma mais eficiente (RIPLEY et al., 2004; BOWN et al., 2009a). Os valores de $\mathrm{PI}_{\mathrm{ABS}}$ e $\mathrm{PI}_{\text {total }}$ foram maiores nas plantas sob alta irradiância e fertilizadas com fósforo, indicando que foram eficientes no uso e dissipação do excesso da energia. Em geral, plantas adaptadas a maior irradiância apresentam maior capacidade de transporte de elétrons (GYMAH et al., 2003; LICHTENTHALER et al., 2007).

A deficiência de fósforo também diminuiu a taxa fotossintética, conforme demonstrado para diversas espécies em vários trabalhos (REICH et al., 2009; WARREN, 2011; WU et al., 2014). Essa diminuição da fotossíntese ocorre devido a uma limitação promovida sobre regeneração da RuBP (indicada por $\mathrm{J}_{\max }$ ) e /ou a quantidade ou atividade da enzima (indicada por $\mathrm{V}_{\text {cmax }}$ ) (WARREN, 2011). Rao et al. (1989) relataram que a redução da regeneração da RuBP em folhas deficientes em fósforo, não foi limitado pelo suprimento de ATP e NADPH, mas limitado pela maior proporção de carbono desviado para a síntese amido.

As taxas de fotossíntese máxima foram maiores nas plantas submetidas à alta irradiância, independente dos tratamentos de fertilização. Resultados semelhantes foram observados para outras espécies arbóreas (GYIMAH; NAKAO, 2007; ROSSATO et al., 2010).

A fertilização com fósforo teve efeitos positivos na condutância estomática, em ambos os ambientes de irradiância. Resultados semelhantes foram observados em duas espécies tropicais de sub-bosque Randia canthioides e Cryptocarya concinna, em que a aplicação de fósforo na floresta por 36 meses, estimulou a condutância estomática para as duas espécies (ZHU et al., 2014). O baixo teor de fósforo foliar pode reduzir a condutância estomática, como tem mostrado alguns estudos experimentais em regime controlado (SINGH et al., 2013), enquanto outros estudos sugerem não haver relações diretas entre a condutância estomática e os efeitos do fósforo na fotossíntese (BOWN et al., 2009b; WARREN, 2011). Estudos adicionais com outras espécies são requeridos para estabelecer a relação de causa e efeito entre P e gs. Outra abordagem sugere que a deficiência de fósforo pode estar afetando a condutância estomática devido a sua relação com características morfológicas e anatômicas da folha alteradas por causa da limitada expansão foliar (TERASHIMA et al., 2006; SEKIYA; YANO, 2008).

O aumento de gs implicou em aumento na transpiração. As maiores taxas de transpiração foram observadas paras as plantas fertilizadas, nos dois ambientes de luminosidade. Resultados seme- 
lhantes foram observados em mudas de Alseis blackiana em que a fertilização com fósforo na floresta por 10 anos aumentou significativamente as taxas de transpiração desta espécie (PASQUINI; SANTIAGO, 2012).

O rendimento quântico foi menor nas plantas não fertilizadas e submetidas à alta irradiância. Isto sugere reduzida capacidade do sistema fotossintético em utilizar fótons para assimilação de $\mathrm{CO}_{2}$ e indica que a deficiência de fósforo pode afetar as reações fotoquímicas da fotossíntese (BRAHIM et al., 1996; SINGH et al., 2013).

Portanto, a redução da taxa fotossintética sob deficiência de P, implicou na redução da produção de massa seca pelas plantas em ambos os ambientes de irradiância, como conseqüência da redução do transporte de elétrons na etapa fotoquímica $\left(\mathrm{F}_{\mathrm{v}} / \mathrm{F}_{\mathrm{m}} ; \mathrm{PI}_{\mathrm{ABS}}\right.$ e $\left.\mathrm{PI}_{\text {total }}\right)$, bem como da redução da condutância estomática, da área foliar e da regeneração da Rubisco na etapa bioquímica da fotossíntese. Diante dessas informações para a espécie O. pyramidale, se faz necessário aprofundar os conhecimentos sobre as demandas de irradiância e fertilização fosfatada nas plantas jovens (mudas) sob condições de campo e, do ponto de vista aplicado, a utilização dessa abordagem ecofisiológica com plantas transferidas de ambientes sombreados para ambientes abertos e vice-versa, seria interessante por ter relação com práticas silviculturais, simulando condições de desbastes ou de fechamento de copa resultante do processo de recuperação da área degradada ou mesmo em plantios de produção.

\section{CONCLUSÕES}

A deficiência de P e a baixa irradiância podem afetar intensa e negativamente a fotossíntese, $\mathrm{o}$ acúmulo de biomassa e o crescimento de plantas jovens de O. pyramidale. Nas plantas com deficiência de $\mathrm{P}$ a redução da massa seca foi relacionada com a limitação da fotossíntese, devido à redução da eficiência no transporte de elétrons, além de ter sido afetada pela redução da área foliar e diminuição da condutância estomática. Portanto, a fertilização com fósforo na concentração (1 mM) e irradiância máxima em torno de $1200-1400 \mu \mathrm{mol} \mathrm{m}^{-2} \mathrm{~s}^{-1}$ promoveram aumentos significativos no crescimento e no acúmulo de biomassa de plantas jovens de O. pyramidale sincronizados com aumentos da fotossíntese.

\section{AGRADECIMENTOS}

Os autores agradecem aos pesquisadores do Laboratório de Fisiologia e Bioquímica Vegetal do Instituto Nacional de Pesquisas da Amazônia (MCTI-INPA) e ao Conselho Nacional de Desenvolvimento Científico e Tecnológico (CNPq) pelo suporte durante o desenvolvimento do trabalho e pelo financiamento da pesquisa, respectivamente. J.F.C. Gonçalves é bolsista de produtividade CNPq.

\section{REFERÊNCIAS BIBLIOGRÁFICAS}

AZEVEDO, C. G. F. Phtosynthetic parameters and growth in seedlings of Bertholletia excelsa and Carapa guianensis in response to pre-acclimation to full sunlight and mild water stress. Acta amazônica, Manaus, v. 44, n. 1, p. 67-77, 2014.

BARBOSA, A. P.; SAMPAIO, P. T. B.; CAMPOS, M. A.; VARELA, V. P.; GONÇALVES, C Q. B.; IIDA, S. Tecnologia alternativa para a quebra de dormência das sementes de pau de balsa (Ochroma lagopus Sw. Bombacaceae). Acta Amazônica, Manaus, v. 34, n. 1, p. 107-110, 2004.

BLOOMFIELD, K. J.; FARQUHAR, G. D.; LLOYD, J. Photosynthesis-nitrogen relationships in tropical forest tree species as affected by soil phosphorus availability: a controlled environment study. Functional Plant Biology, v. 41, n. 8, p. 820-832, 2014.

BOWN, H. E.; MASON, E. G.; CLINTON, P. W.; WATT, M. S. Chlorophyll fluorescence response of Pinus radiate clones to nitrogen and phosphorus supply. Ciência de Investigação Agrária, v. 36, n. 3, p. 451-464, 2009A. 
Cunha et al. - Biomassa, trocas gasosas e aspectos nutricionais de plantas jovens de pau de balsa (Ochroma pyramidale (Cav. Ex Lamb.) Urb.) submetidas à fertilização fosfatada em ambientes contrastantes de irradiância

BOWN, H. E.; WATT, M. S.; MASON, E. G. The influence of nitrogen and phosphorus supply on mesophyll conductance limitations to photosynthesis in Pinus radiata. Tree Physiology, Victoria, v. 29, n. 9, p. 11431151, 2009B.

BRAHIM, M. B.; LOUSTAU, D.; GOUDILLERE, J. P.; SAUR, E. Effects of phosphate deficiency on photosynthesis and accumulation of starch and soluble sugars in 1 year old seedlings of maritime pine (Pinus pinaster Ait). Annals of Forest Science, Nancy, v. 53, n. 4, p. 801-810, 1996.

BUGBEE, B. G. Growth, analyses and yield components. In: SALISBURY, F. B. (Ed). Units, Symbols and Terminology for plant physiology, New York: Oxford University Press, 1996. p. 115-119.

CARVALHO, N. O. S.; PELACANI, C. R.; RODRIGUES, M. O. S.; CREPALDI, I. Crescimento inicial de plantas de licuri (Syagrus coronata) em diferentes níveis de luminosidade. Revista Árvore, Viçosa, v. 30, n. 3, p. 351$357,2006$.

CHENG, L.; TANG, X.; VANCE, C.; WHITE, P. J.; ZANG, F.; SHEN, J. Interactions between light intensity and phosphorus nutrition affect the phosphate-mining capacity of white lupin (Lupinus albus). Journal of Experimental Botany, Oxford, v. 65, n. 12, p. 2995-3003, 2014.

COSTA, S. G.; MORATO, E. F.; SALIMON, C. I. Densidade de bambu e estrutura populacional de duas espécies arbóreas pioneiras em florestas secundárias de diferentes idades em um remanescente florestal, Acre. Scientia Forestalis, Piracicaba, v. 40, n. 95, p. 363-374, 2012.

CRAVEN, D.; DENT, D.; BRADEN, D.; ASHTON, M. S.; BERLYN, G. D.; HALL, J. S. Seasonal variability of photosynthetic characteristics influences growth of eight tropical tree species at two sites with contrasting precipitation in Panama. Forest Ecology and Management, Amsterdam, v. 261, n. 10, p. 1643-1653, 2011.

CRUZ, C. A. F.; PAIVA, H. N.; CUNHA, A. C. M. C. M.; NEVES, J. C. L. Produção de mudas de Canafístula cultivadas em latossolo vermelho amarelo álico em resposta a macronutrientes. Cerne, Lavras, v. 18, n. 1, p. 87-98, 2012.

DAHLGREN, J. P.; ERIKSON, O.; BOLMGREN, K.; STRINDELL, M.; EHRLÉN, J. Specific leaf area as a superior predictor of changes in field layer abundance during forest sucession. Journal of Vegetation Science. v. 17, n. 5, p. 577-582, 2006.

DESOTGIU, R.; POLLASTRINI, M.; CASCIO, C.; GEROSA, G.; MARZUOLI, R.; BUSSOTTI, F. Chlorophyll a fluorescence analysis along a vertical gradient of the crown in a poplar (Oxford clone) subjected to ozone and water stress. Tree Physiology, Victoria, v. 32, n. 8, p. 976-986, 2012.

DOMINGUES, T. F.; MEIR, P.; FELDPAUSCH, T. R.; SAIZ, G.; VEENENDAAL, E. M.; SCHRODT, F.; BEID, M.; DJAGBLETEY, G.; HIEN, F.; CAMPAORE, H.; DIALLO, A.; GRACE, J.; LLOYD, J. Co-limitation of photosynthetic capacity by nitrogen and phosphorus in West capacity by nitrogen and phosphorus in West Africa Woodlands. Plant, Cell and Environment, Oxford, v. 33, n. 6, p. 959-980, 2010.

EVANS, J. R.; POORTER, H. Photosynthetic acclimation of plants to growth irradiance: the relative importance of SLA and nitrogen partitioning in maximizing carbon gain. Plant Cell and Environmental, Oxford, v. 24, n. 8 , p. $755-767,2001$.

FERNANDES, A. R.; BRAZ, A. M. S.; MAIA, P. R.; VIÉGAS, I. J. M. Phosphorus fertilization and base saturation in the formation of Swietenia macrophyla seedlings. Revista de Ciências Agrárias, Belém, v. 56, n. 3, p. 261$267,2013$.

FERREIRA, M. J.; GONÇALVES, J. F. C.; FERRAZ, J. B. S. Crescimento e Eficiência do uso da água de plantas jovens de castanheira da Amazônia em área degradada e submetidas à adubação. Ciência Florestal, Santa Maria, v. 22, n. 2, p. 393-401, 2012. 
FONTES, A. G.; GAMA-RODRIGUES, A. C. G.; GAMA RODRIGUES, E. F. Eficiência nutricional de espécies arbóreas em função da fertilização fosfatada. Pesquisa Florestal Brasileira, Colombo, v. 33, n. 73, p. 9-18, 2013.

FREDEEN, A. L.; RAO, I. M.; TERRY, N. Influence of Phosphorus Nutrition on Growth and Carbon Partitioning in Glycine max. Plant Physiology, Bethesda, v. 89, n. 1, p. 225-230, 1988.

GLEASON, S. M.; ARES, J. R. A. Biomass allocation and phosphorus economics of rain forest seedlings: effects of fertilization and radiation on soil specialists and soil generalists. Journal of Tropical Ecology, Cambridge, v. 27, n. 2 , p. 147-161, 2011.

GONÇALVES, J. F. C.; SANTOS JÚNIOR, U. M. Utilization of the chlorophyll a fluorescence technique as a tool for selecting tolerant species to environments of high irradiance. Brazilian Journal of Plant Physiology, v. 17, n. 3, p.307-313, 2005.

GONÇALVES, J. F. C.; SILVA, C. E. M.; JUSTINO, G. C.; NINA JR., A. R. Efeito do ambiente de luz no crescimento de plantas jovens de mogno (Swietenia macrophyla King). Scientia Forestalis, Piracicaba, v. 40, n. 95, p. 337344, 2012.

GONÇALVES, J. F. C.; VIEIRA, G.; MARENCO, R. A.; FERRAZ, J. B.; SANTOS JR., U. M.; BARROS, F. C. Nutritional status and specific area of mahogany and tonka bean under two light environments. Acta Amazônica, Manaus, v. 35, n. 1, p. 23-27, 2005.

GYMAH, R.; NAKAO, T. Early growth and photosynthetic responses to light in seedlings of three tropical species differing in successional strategies. New Forests, Amsterdam, v. 33, n. 3, p. 217-236, 2007.

GYMAH, R.; NAKAO, T.; ZAW, M. Effects of Light Intensity and Nutrient on Growth and Electron Transport Rate of Tropical tree Seedlings found in Ghana. Bulletin of the Faculty of Agriculture, Miyazaki, v. 49, n. 1-2, p. $69-78,2003$.

HOAGLAND, D. R, ARNON, D. I. The water culture method for growing plants without soil. University of California. Agricultural Soil. University of California. Bekerley: CAES, 1950, 32 p. (Circular, 347).

JAQUETTI, R. K.; GONÇALVES, J. F. C.; FERRAZ, J. B. S.; FERREIRA, M. J.; SANTOS JUNIOR, U. M.; LACERDA, C. F. Green Fertilization enhances the photosynthetic performance and the growth of leguminous trees for restoration plantation in Central Amazon. American Journal of Plant Sciences, v. 5, n. 16, p. 2497-2508, 2014.

KAVANOVÁ, M.; LATTANZI, F. A.; GRIMOLDI, A. A.; SCHNYDER, H. Phosphorus deficiency decreases cell division and elongation in grass leaves. Plant Physiology, Bethesda, v. 141, n. 2, p. 766-775, 2006.

LAMBERS, H.; RAVEN, J.; SHAVER, G. R.; SMITH, S. E. Plant nutrient-acquisition strategies change with soil age. Trends in Ecology and Evolution, Amsterdam, v. 23, n. 2, p. 95-103, 2008.

LICHTENTHALER, H. K.; MAREK, M. V.; KALINA, T.; URBAN, O. Differences in pigment composition, photosynthetic rates and chlorophyll fluorescence imagens of sun and shade leaves of four tree species. Plant Physiology Biochemistry, v. 45, n. 8, p. 577-588, 2007.

MENDONÇA SANTOS, M. L.; SANTOS, H. G.; COELHO, M. R.; BERNARDI, A. C. C.; MACHADO, P. L. O. A.; MANZATTO, C. V.; FIDALGO, E. C. C. C. Soil and Land Use in the Brasilian Amazon. In: MOREIRA, F.; SIQUEIRA, J.; BRUSSAARD, L. (Ed.). Soil Biodiversity in Amazon and Other Brasilian Ecossystems, Cambridge: CABI Publishing, 2006. p. 13-42.

QUESADA, C. A.; PHILIPS, O. L.; SCHUWARZ, M.; CZIMEZIKCL, BAKER, T.R., PATINO, S. FYLLAS, N. M.; HODNETT, M.G.; HERRERA, R.; ALMEIDA, S. et al. Basin wide variation in Amazon forest structure and function are mediated by both soils and climate. Biogeosciences, v. 9, n. 6, p. 2203-2246, 2012. 
Cunha et al. - Biomassa, trocas gasosas e aspectos nutricionais de plantas jovens de pau de balsa (Ochroma pyramidale (Cav. Ex Lamb.) Urb.) submetidas à fertilização fosfatada em ambientes contrastantes de irradiância

HERNÁNDEZ; I.; MUNNÉ-BOSCH, S. Linking phosphorus availability with photo-oxidative stress in plants. Journal of Experimental Botany. Oxford, v. 66, n. 10, p. 2889-2900, 2015.

LEE, K. A.; LEE, S. H.; WOO, S. Y. Rubisco activity and gene expression of tropical tree species under light stress. African Journal of Biotechnology, v. 12, n. 20, p. 2764-2769, 2013.

LIMA, M. A. O.; MIELKE, M. S.; LAVINSKY, A. O.; FRANÇA, S.; ALMEIDA, A. F; GOMES, F. P. Crescimento e plasticidade fenotípica de três espécies arbóreas com uso potencial em sistemas agroflorestais. Scientia Forestalis, Piracicaba, v. 38, n. 87, p. 527-534, 2010.

LIMA, J. D.; SILVA, M. S.; MORAES, W. S.; DANTAS, V. A. A.; ALMEIDA, C. C. Efeitos da luminosidade no crescimento de mudas de Caesalpinioideae. Acta Amazonica, Manaus, v. 38, n. 1, p. 5-10, 2008.

MAATHUIS, F. J. M. Physiological functions of mineral macronutrients. Current opinion in Plant Biology, v. 12, n. 3, p. 250-258, 2009.

MARENCO, R. A.; GONÇALVES, J. F. C.; VIEIRA, G. Photosynthesis and leaf nutrients contents in Ochroma pyramidale (Bombacaceae). Photosynthetica, v. 39, n. 4, p. 539-543, 2001.

MIDGLEY, S.; BLYTH, M.; HOWCROFT, N.; MIDGLEY, D.; BROWN, A. Balsa: biology, production and economics in Papua New Guinea. Camberra: ACIAR, 2010. 98 p. (Technical Reports, 73).

MIYAZAWA, M.; PAVAN, M. A.; MURAOKA, T.; CARMO, C. A. F. S.; MELLO, W. J. Chemical analysis of plant tissues. In: SILVA, F. C. Manual de análises químicas de solos, plantas e Fertilizantes. Brasília: EMBRAPA, 1999. p. 172-223.

OOSTERHUIS, D. M.; BIBI, A. C.; GONIAS, E. D.; MOZAFFARI, M. Effect of phosphorus deficiency on cotton physiology. In: OOSTERHUIS, D. M. (Ed.) Summaries of Arkansas Cotton Research 2007. Fayetteville: AAES, p. 35-38, 2008. (Research Series, 562)

PASQUINI, S. C.; SANTIAGO, L. S. Nutrients limit photosynthesis in seedlings of a lowland tropical Forest tree species. Oecologia, Berlin, v. 168, n. 2, p. 311-319, 2012.

PEREIRA, D. C.; BARROS, C. F.; SCARANO, F. R. In situ variation in leaf anatomy and morphology of Andira legalis (Leguminosae) in two neighbouring but contrasting light environments in a Brazilian sandy coastal plain. Acta Botanica Brasilica, São Paulo, v. 23, n. 1, p. 267-273, 2009.

PLASSARD, C.; DELL, B. Phosphorus nutrition of mycorrhizal trees. Tree Physiology, Victoria, v. 30, n. 9, p. 1129-1139, 2010.

POORTER, H.; NICLAS, K. J.; REICH, P. B.; OLEKSYN, J.; POOT, P.; MOMMER, L. Biomass allocation to leaves, stems and roots: meta analyses of interspecific variation and environmental control. New Phytologist, Oxford, v. 193, n. 1, p. 30-50, 2012.

RAO, M.; ARULANANTAHM, R.; TERRY, N. Leaf phosphate status, photosynthesis and carbon partitioning in sugar beet. II Diurnal changes in sugar phosphates, adenylates, and nicotinamide nucleotides. Plant Physiology, Victoria, v. 90, n. 3, p. 820-826, 1989.

REICH, P. B.; OLEKSYN, J.; WRIGHT, I. J. Leaf phosphorus influences the photosynthesis-nitrogen relation: a cross-biome analysis of 314 species. Oecologia, v. 160, n. 2, p. 207-212, 2009.

REICH, P. B.; WHL, C.; WALTERS, M. B.; ELLSWORTH, D. S. Leaf lifespan as a determinant of leaf structure and function Among 23 Amazonian tree species. Oecologia, Berlin, v. 86, n. 1, p. 16-24, 1991. 
RIPLEY, B. S.; REDFERN, S. P.; DAMES, J. Quantification of the photosynthetic performance of phosphorusdeficient Sorghum by means of chlorophyll a fluorescence kinetics. South African Journal of Science, Pretoria, v. 100, p. 615-618, 2004.

RONQUIM, C. C.; PRADO, C. H. B. A.; SOUZA, J. P. Growth, photosynthesis and leaf water potencial in Young plants of Copaifera langsdorffii under contrasting irradiances. Brazilian Journal of Plant Physiology, v. 21, n. 3, p. 97-208, 2009.

ROSSATO, D. R.; TAKAHASHI, F. S. C.; SILVA, L. C. R.; FRANCO, A. C. Características funcionais de folhas de sol e sombra de espécies arbóreas em uma mata de galeria no Distrito Federal, Brasil. Acta Botanica Brasilica, São Paulo, v. 24, n. 3, p. 640-647, 2010.

SANO, T. S.; AMINA, S. I.; NAGATA, T. Phosphate as a limiting factor for the cell division Tobacco BY-2 cells. Plant and Cell Physiology, Oxford, v. 40, n. 1, p. 1-18, 1999.

SANTOS, R. A.; TUCCI, C. A.; HARA, F. A. S.; SILVA, W. G. S. Adubação fosfatada para a produção de mudas de mogno (Swietenia macrophylla King). Acta Amazônica, Manaus, v. 38, n. 3, p. 453-458, 2008.

SANTOS JR., U. M.; GONÇALVES, J. F. C; FEARNSIDE, P. M. Measuring the impact of flooding on Amazonian trees: photosynthetic response models for ten species flooded by hydroelectric dams. Trees, New York, v. 27, n. 1, p. 193-210, 2013.

SANTOS JR., U. M.; GONÇALVES, J. F. C.; FELDPAUSCH, T. R. Growth, leaf nutrient concentration and photosynthetic nutrient use efficiency in Tropical tree species planted in degraded areas in Central Amazonia. Forest Ecology and Management, Amsterdam, v. 226, n. 1-3, p. 299-309, 2006.

SARDANS, J.; PENUELAS, J.; RODA, F. Plasticity of leaf morphological traits, leaf nutrient content, and water capture in the Mediterranean evergree oak Quekus ilex subsp. ballota in response to fertilization and changes in competitive conditions. Ecoscience, v. 13, n. 2, p. 258-270, 2006.

SCHURMANN, P. Redox Signaling in the Chloroplast: The Ferredoxin/Thieoredoxin System. Antioxidants, v. 5, n. 1, p. 69-78, 2003.

SEKIYA, N.; YANO, K. Stomatal density of cowpea correlates with carbon isotope discrimination in different phosphorus, water and $\mathrm{CO}_{2}$ environments. New Phytologist, Oxford, v. 179, n. 3, p. 799-807, 2008.

SINGH, K.; BADGUJAR, G. B.; REDDY, V. R.; FLEISHER, D. H.; TIMLIN, D. J. Effect of phosphorus Nutrition on Growth and Physiology of Cotton Under Ambient and Elevated Carbon Dioxide. Journal of Agronomy and Crop Science, v. 199, n. 6, p. 436-448, 2013.

STRASSER, R. J.; TSIMILLI-MICHAEL, M.; QIANG, S.; GOLTSEV, V. Simultaneous in vivo recording of prompt and delayed fluorescence and 820-nm reflection changes during drying and after rehydration of the resurrection plant Haberlea rhodo pensis. Biochimica et Biophysica Acta, v. 1797, n. 1, p. 1313-1326, 2010.

STRASSER, R. J.; TSIMILLI-MICHAEL, M.; SRIVASTAVA, A. Analysis of the chlorophyll a fluorescence transient. In: PAPAGEORGIOU, G. C.; GOVINDJEE (Ed.). Chlorophyll a Fluorescence: A Signature of photosynthesis, Dordrecht: Springer, 2004. p. 321-362.

TERASHIMA, I.; HANBA, Y. T.; TAZOE, Y.; VYAS, P.; YANO, S. Irradiance and phenotype: comparative ecodevelopment of sun and shade leaves in relation to photosynthetic $\mathrm{CO}_{2}$ diffusion: Journal of Experimental Botany, Oxford, v. 57, n. 2, p. 342-354, 2006.

VALLADARES, F; WRIGHT, S. J.; LASSO, E.; KITAJIMA, K.; PEARCY, R. W. Plastic phenotypic response to light of 16 congeneric shrubs from a panamanian rainforest. Ecology, Washington, v. 81, n. 7, p. 1925-1936, 2000. 
Cunha et al. - Biomassa, trocas gasosas e aspectos nutricionais de plantas jovens de pau de balsa (Ochroma pyramidale (Cav. Ex Lamb.) Urb.) submetidas à fertilização fosfatada em ambientes contrastantes de irradiância

VITTI, G. C.; FERREIRA, A. C. Síntese de análises químicas em tecido vegetal. Piracicaba: ESALQ-DS, 1997.

TOWNSEND, A. R.; Cleveland, C. C.; HOULTON, B. Z.; ALDEN, C. B.; WHITE, J. W. C. Multi-element regulation of the tropical forest carbon cycle. Frontiers in Ecology and the Environment, v. 9, n. 1, p. 9-17, 2011.

WARREN, C. R. How does P affect photosynthesis and metabolite profiles of Eucalyptus globules? Tree Physiology, Victoria, v. 31, n. 7, p. 727-739, 2011.

WIKA, T.; ROBAKOWISKI, P.; ZYTKOWIAK, R. Acclimation of leaves to contrasting irradiance in juvenile trees differing in shade tolerance. Tree Physiology, Victoria, v. 27, n. 9, p. 1293-1306, 2007.

WU, P. F.; MA, X.; TIGABU, M.; HUANG, Y.; ZHOU, L.; CAI, L.; HOU, X.; ODEN, P. C. Comparative accumulation and photosynthetic rate of seven species of Eucalypt in response to phosphorus supply. Journal of Forestry research, v. 25, n. 2, p. 377-383, 2014.

ZAHAWI, R. A.; ECKERT, C.; CHAVES-FALLAS, J. M.; SCHWANITZ, L.; ROSALES, J. A.; HOLL, K. D. The effect of restoration treatment soils and parent tree on tropical forest tree seedling growth. Open Journal of Forestry, v. 5, n. 2, p. 154-161, 2015.

ZHU, F.; LU, X.; MO, J. Phosphorus limitation on photosynthesis of two dominant understory species in a lowland forest. Journal of Plant Ecology, v. 7, n. 6, p. 526-534, 2014.

Recebido em 04/11/2014

Aceito para publicação em 20/08/2015 